\title{
EFEITO DO NITROGÊNIO SOBRE A QUALIDADE FISIOLÓGICA, PRODUTIVIDADE E CARACTERÍSITICAS DE SEMENTES DE FEIJÃO ${ }^{1}$
}

\author{
CARLOS ALEXANDRE COSTA CRUSCIOL², EDUARDO DOVALLE LIMA ${ }^{3}$, MARCELO ANDREOTTI ${ }^{4}$, JOÃO NAKAGAWA 5 , \\ LEANDRO BORGES LEMOS ${ }^{6}$, OSWALDO MASSUO MARUBAYASHI ${ }^{7}$
}

\begin{abstract}
RESUMO - Os resultados da adubação com N sobre a produtividade de feijão são controvertidos. A maioria dos trabalhos não estuda o efeito do $\mathrm{N}$ sobre a qualidade fisiológica e o tamanho das sementes. Um experimento foi realizado no município de São Manuel (SP), no ano agrícola de 1993/94, em Latossolo Vermelho-Amarelo, utilizando-se a cv. IAC-Carioca, visando estudar a influência da combinação de doses de $\mathrm{N}\left(0,0 ; 12,5\right.$ e $\left.25,0 \mathrm{~kg} \mathrm{ha}^{-1}\right)$ na semeadura e em cobertura sobre a qualidade fisiológica, produtividade e tamanho das sementes. O delineamento experimental foi de blocos casualisados em esquema fatorial 3x3, com 4 repetições. Foram avaliados os componentes da produção ( $\mathrm{n}^{\circ}$ de sementes/planta e massa de 100 sementes), a produtividade, a germinação e o vigor ( $1^{\text {a }}$. contagem, índice de velocidade de germinação e condutividade elétrica), e o tamanho das sementes. Não houve efeito de interação entre doses de $\mathrm{N}$ na semeadura com as de cobertura nas variáveis analisadas. As doses de $\mathrm{N}$ não mostraram efeito favorável sobre a germinação e o vigor das sementes. O fornecimento de $25,0 \mathrm{~kg} \mathrm{ha}^{-1} \mathrm{de} \mathrm{N}$ na semeadura proporcionou o aumento dos componentes da produção, mas sem elevar a produtividade. A disponibilidade de $\mathrm{N}$, pela adubação de cobertura, aumentou o tamanho das sementes.

Termos para indexação: Phaseolus vulgaris L., nutrição mineral, qualidade de semente, classificação de semente.
\end{abstract}

\section{NITROGEN EFFECT ON THE PRODUCTIVITY, PHYSIOLOGICAL QUALITY AND CHARACTERISTICS OF DRY BEAN SEED}

\begin{abstract}
The results of fertilizing with $\mathrm{N}$ on bean yield are questionable, and most of the works does not study the effect of the $\mathrm{N}$ on the physiologic seed quality and size (screen grading). The experiment was set out in São Manuel, SP, Brazil, in the agricultural year 1993/94, on a Yellow Red Latosol (Haplorthox) using bean cultivar IAC-Carioca, in randomized blocks design with four replications. The objective of this research was to study three rates of $\mathrm{N}(0,0 ; 12,5$ and $25,0 \mathrm{~kg} \mathrm{ha}^{-1}$ ) applied at seed sowing time, combined with the same rates broadcasted after seedling emergence. At harvest the following characteristics were evaluated: yield components (number of seeds per plant and one hundred seeds weight), seeds yield, percentage of germination, first counting germination percentage, germination speed index and electrical conductivy. There was no significant effect of the interaction of $\mathrm{N}$ applied at seed sowing times broadcasting. Applied $\mathrm{N}$ rates did not shown any favorable effects on seed germination and seed vigor. Supplying $25,0 \mathrm{~kg} \mathrm{ha}^{-1}$ of $\mathrm{N}$ at sowing time increased yield components, without increasing yield. Availability of $\mathrm{N}$, due to broadcasted fertilizer increased seed size.
\end{abstract}

Index terms: Phaseolus vulgaris, mineral nutrition, seed quality, classification of seed.

\footnotetext{
${ }^{1}$ Aceito para publicação em 23.07.2003.

${ }^{2}$ Prof. Adjunto, Dpto. de Produção Vegetal-DPV, Faculdade de Ciências Agronômicas-FCA/UNESP, Cx. Postal 237, CEP 18603-970, Botucatu, SP; bolsista CNPq; e-mail: crusciol@fca.unesp.br

${ }^{3}$ Eng. Agr., MSc., Faculdade de Ciências Agrárias do Pará, CEP 66077530, Belém, PA; bolsista CAPES/PICDT/FCAP; e-mail: valle@fca.unesp.br
} ${ }^{4}$ Prof. Assistente Dr., Centro de Ciências Agrárias-CCA/UNIOESTE,
85960-000, Marechal Cândido Rondon(PR); e-mail: andreotti@unioeste.br
${ }^{5}$ Prof. Titular, DPV, FCA/UNESP, Botucatu, SP; bolsista CNPq; e-mail:
secdamv@fca.unesp.br
${ }^{6}$ Prof. Assistente Dr., DPV, FCA/UNESP, Botucatu, SP; e-mail:
leandrobl@fca.unesp.br
${ }^{7}$ Prof. Assistente Dr., Faculdade de Ciências Agrárias/UNOESTE, CEP
19067-175, Presidente Prudente, SP. 


\section{INTRODUÇÃO}

O feijoeiro no Brasil é cultivado, praticamente, durante o ano inteiro, sendo a primeira época de cultivo chamada feijão “das águas”, responsável por aproximadamente 50\% da área plantada, representando $45 \%$ da produção nacional e com produtividade média de $560 \mathrm{~kg} \mathrm{ha}^{-1}$ (Yokoyama et al., 2000). Comparando-se com as produtividades de milho, arroz e soja, constata-se que a cultura do feijão possui o menor rendimento por unidade de área.

É essencial para o aumento da produtividade, a melhoria do nível tecnológico do feijoeiro, na qual inclui-se o emprego de sementes de alta qualidade (Bragantini, 1996 e Yokoyama et al., 2000). A qualidade de sementes pode ser expressa pela interação de quatro componentes: genético, físico, sanitário e fisiológico (Ambrosano et al., 1999). De acordo com Vieira et al. (1993), o componente fisiológico pode ser influenciado pelo ambiente em que as sementes se formam. Portanto, deve-se considerar a germinação e o vigor, procurando-se diferenciar sementes com maior potencial fisiológico, em função de tratos culturais aplicados, como a adubação mineral (Andrade et al., 1999).

Segundo Delouche (1981), para se obter sementes de alta qualidade é indispensável a realização de adubação mineral adequada. No entanto, trabalhos que objetivam relacionar adubação e nutrição das plantas com a qualidade fisiológica das sementes são em número reduzido e os resultados nem sempre são concordantes (Carvalho et al., 2001).

A utilização da adubação nitrogenada na cultura do feijão, apesar de prática comum entre os agricultores, é variável no que diz respeito às doses empregadas na semeadura e em cobertura (Valério et al., 1999). Nos últimos anos diversos pesquisadores têm-se preocupado em estudar os efeitos de doses, parcelamentos, épocas e modo de aplicação de fertilizantes nitrogenados para o feijoeiro e seus reflexos na produtividade. Contudo, a maioria dos trabalhos relacionados com a adubação e a nutrição mineral do feijoeiro, não estudaram o efeito do $\mathrm{N}$ sobre a qualidade fisiológica das sementes (Andrade et al., 1999).

Para Carvalho \& Nakagawa (2000), o N pode influenciar na qualidade fisiológica das sementes, mas os seus efeitos variam com as condições ambientais e o estádio de desenvolvimento da planta em que ocorre a aplicação do fertilizante. Fica evidente a necessidade da execução de mais estudos sobre a adubação/nutrição e a qualidade fisiológica das sementes de feijão, objetivando não só a qualidade, mas, também, a elevação da produtividade (Carvalho et al., 2001).
A pesquisa evidencia a possibilidade de aumentar-se a produtividade do feijão, com a utilização dos fertilizantes nitrogenados (Carvalho et al., 1998a). A aplicação de N-mineral nos solos tropicais pode resultar, às vezes, em baixa freqüência de resposta pelo feijoeiro (Vieira, 1998). Ambrosano et al. (1996) verificaram respostas diferentes para a aplicação de doses de $\mathrm{N}$ de um ano para o outro. De modo geral, tem sido constatada resposta do feijoeiro ao $\mathrm{N}$, embora a freqüência e a amplitude variem de região para região, e ainda dentro da mesma região, em função do clima e das condições fitossanitárias da cultura (Almeida et al., 2000).

Quanto à classificação de sementes de feijão por tamanho, dentro de uma mesma cultivar, pode ser uma estratégia para elevar a germinação, o vigor e a produtividade. Dentre a série de fatores que está relacionada com o vigor destaca-se o tamanho das sementes, que pode exprimir o seu nível de qualidade fisiológica (Carvalho \& Nakagawa, 2000), pois, normalmente, sementes bem formadas originam plântulas mais vigorosas (Delavale et al., 1999), as quais teriam possibilidade de afetar os componentes da produção e a produtividade. Além disso, a classificação de lotes de sementes por tamanho beneficia a precisão da semeadura mecânica, com conseqüente economia desse insumo, e melhora o aspecto visual do lote a ser comercializado (Lima \& Carmona, 1999).

Os efeitos, que o tamanho de sementes exerce sobre o comportamento da própria semente e da plântula, vêm sendo estudados há bastante tempo, visando identificar diferenças de qualidade (Delavale et al., 1999). Independente do efeito do tamanho da semente na qualidade fisiológica e performace no campo, a classificação das sementes, segundo padrões préfixados, constitui um requisito básico para favorecer o manuseio, racionalizar a comercialização, agregar valor ao produto e facilitar a estocagem (Puzzi, 1986 e Lima \& Carmona, 1999).

O presente estudo teve como objetivo avaliar, na cultura do feijão, cultivar IAC-Carioca, a influência de doses de $\mathrm{N}$ na semeadura e em cobertura sobre a qualidade fisiológica, produtividade e tamanho das sementes.

\section{MATERIAL E MÉTODOS}

O trabalho foi realizado no ano agrícola de 1993/94 (cultivo “das águas”), na Fazenda Experimental São Manuel, pertencente à Faculdade de Ciências Agronômicas-FCA, Campus de Botucatu/UNESP, localizada no município de São Manuel (SP), apresentando coordenadas geográficas de $48^{\circ}$ $34^{\prime}$ 'de longitude oeste de Greenwich e $22^{\circ} 44^{\prime}$ 'de latitude 
sul, com altitude de $750 \mathrm{~m}$. O solo da área experimental é classificado como Latossolo Vermelho-Amarelo, distrófico, textura média (EMBRAPA, 1999). A precipitação média anual é de $1433 \mathrm{~mm}$, sendo que a precipitação pluvial total, durante todo o ciclo de cultivo do feijão, foi de $561 \mathrm{~mm}$, a temperatura média nesse mesmo período foi de $23,2^{\circ} \mathrm{C}$, e a umidade relativa média anual é de $71,5 \%$.

A composição granulométrica do solo, na profundidade de 0 a $0,20 \mathrm{~m}$, é de $84 \%$ de areia, $1 \%$ de silte e $15 \%$ de argila. Os atributos químicos do solo, na mesma camada, antes da instalação do experimento, apresentaram os seguintes resultados: $\mathrm{pH}\left(\mathrm{CaCl}_{2}\right)=4,8$; M.O. $=6,5 \mathrm{~g} \mathrm{dm}^{-3} ; \mathrm{P}($ resina $)=$ 21,7 $\mathrm{mg} \mathrm{dm}^{-3} ; \mathrm{K}$, Ca e Mg trocáveis, H+Al, SB e CTC = 1,4; 12; 7; 23,3; 20 e $44 \mathrm{mmol}_{\mathrm{c}} \mathrm{dm}^{-3}$, respectivamente, e V\% $=47$.

Um mês antes da implantação do experimento (22/10/ 93) foi realizada a correção do solo com calcário dolomítico de PRNT $=90 \%$, visando atingir V\% $=70$. O preparo do solo foi realizado por meio de uma aração e duas gradagens, sendo a primeira logo após a aração e a segunda, pouco antes da semeadura.

O delineamento experimental empregado foi o de blocos ao acaso em esquema fatorial $3 \times 3$, com quatro repetições. Os tratamentos foram constituídos da combinação de três doses de $\mathrm{N}$ na semeadura $\left(0,0 ; 12,5\right.$ e $\left.25,0 \mathrm{~kg} \mathrm{ha}^{-1}\right)$ e de três doses de $\mathrm{N}$ em cobertura $\left(0,0 ; 12,5\right.$ e $\left.25,0 \mathrm{~kg} \mathrm{ha}^{-1}\right)$, fornecidas na forma de sulfato de amônio.

A cultivar utilizada foi a IAC-Carioca, lançada pelo Instituto Agronômico de Campinas em 1972, que ainda se apresenta com grande aceitação no mercado, em função da qualidade do material (Yokoyama et al., 2000). Suas principais características são as sementes de cor bege com estrias marrons, o hábito de crescimento indeterminado (tipo III) e o porte prostrado.

A adubação de semeadura com $\mathrm{P}$ e K, em função da análise de solo, foi de $40 \mathrm{~kg} \mathrm{ha}^{-1}$ de $\mathrm{P}_{2} \mathrm{O}_{5}$ e $30 \mathrm{~kg} \mathrm{ha}^{-1}$ de $\mathrm{K}_{2} \mathrm{O}$, na forma de superfosfato simples e cloreto de potássio.

As parcelas foram constituídas por 8 linhas de $4 \mathrm{~m}$ de comprimento, espaçadas entre si em $0,50 \mathrm{~m}$, correspondendo a uma área total de $16 \mathrm{~m}^{2}$. Como bordadura foram consideradas as duas linhas laterais e mais $0,50 \mathrm{~m}$ em ambas as extremidades de cada linha.

A semeadura foi feita manualmente, no período "das águas”, em 22/11/93, fazendo-se a distribuição de 19 sementes por metro de sulco, com o objetivo de se obter, posteriormente ao desbaste, uma população aproximada de 240.000 plantas ha-1 ${ }^{-1}$ O início da emergência de plântulas deu-se em 28/11/93.
As doses de $\mathrm{N}$ foram aplicadas na semeadura, junto com o P e o K, e em cobertura aos 22 dias após a emergência (DAE) das plantas de feijão, na etapa de desenvolvimento V4, subetapa V4-5, ou seja, quando $50 \%$ das plantas apresentavam a quinta folha trifoliolada da haste principal aberta (Fernández et al., 1985).

Durante o desenvolvimento da cultura, os tratos culturais e fitossanitários foram os recomendados à cultura do feijão. A colheita foi efetuada manualmente em 20/02/94, no final da etapa R9, isto é, na maturação plena (Fernández et al., 1985), totalizando um ciclo biológico de 90 dias.

Da produção total obtida por parcela, consideraram-se como sementes àquelas retidas a partir da peneira de furos oblongos 12/64x3/4” (4,76x19,05mm), após descartadas as impurezas. Além disso realizou-se uma catação manual para eliminar algumas sementes podres, germinadas e descoloridas. Foi determinado o teor de água das sementes pelo método da estufa a $105 \pm 3^{\circ} \mathrm{C} / 24 \mathrm{~h}$ (Brasil, 1992), para corrigir os valores da produtividade das sementes ao teor de $13 \%$ de umidade.

Para a determinação dos componentes da produção (número de sementes por planta e massa de 100 sementes), coletaram-se, aleatoriamente, 10 plantas por área útil de cada parcela. Na avaliação da produção, colheram-se as 6 linhas centrais úteis das parcelas. As plantas arrancadas foram secadas ao ar e trilhadas manualmente, para evitar danos mecânicos às sementes.

As sementes obtidas em cada parcela foram acondicionadas em sacos de papel e mantidas no Laboratório de Análises de Sementes da FCA/UNESP, durante a avaliação da qualidade fisiológica, por meio dos testes de: germinação: utilizando-se quatro subamostras de 50 sementes para cada parcela, semeadas em rolo de papel germitest, umedecido com volume de água equivalente a 2,5 vezes o peso do substrato e mantidas a temperatura de $25^{\circ} \mathrm{C}$, sendo a primeira contagem realizada no $5^{\circ}$ dia após a semeadura e a última avaliação no $9^{\circ}$ dia (Brasil, 1992); primeira contagem do teste de germinação; índice de velocidade de germinação (IVG): obtido em conjunto com o teste de germinação, computando-se diariamente, a partir do primeiro dia da semeadura até o último dia do teste de germinação, o número de plântulas normais, aplicando-se depois a fórmula proposta por Maguire (1962); condutividade elétrica: utilizando-se três subamostras de 50 sementes para cada parcela, previamente pesadas em balança com precisão de $0,01 \mathrm{~g}$, imersas em um recipiente com $75 \mathrm{ml}$ de água destilada e mantidas em câmara a $25^{\circ} \mathrm{C}$ durante 24 horas (Vieira, 1994). Após esse período, foi feita a leitura da solução do exsudado com auxílio de condutivímetro modelo 
Digimed DM 31, sendo depois calculada a condutividade em $\mu \mathrm{S} \mathrm{cm} \mathrm{cm}^{-1} \mathrm{~g}^{-1}$ de sementes em função do peso inicial das sementes utilizadas (AOSA, 1983).

As sementes colhidas foram classificadas em tamanho, passando-se cada repetição através de jogo de peneiras manual com crivos oblongos. Assim, sete classes de sementes foram obtidas, utilizando-se as peneiras: $12 \times 3 / 4$ " (4,76x19,05mm); 13x3/4" (5,16x19,05mm); 14x3/4 $(5,56 \times 19,05 \mathrm{~mm}) ; 15 \times 3 / 4 \quad(5,95 \times 19,05 \mathrm{~mm}) ; 16 \times 3 / 4$ $(6,35 \times 19,05 \mathrm{~mm}) ; 17 \times 3 / 4(6,75 \times 19,05 \mathrm{~mm})$ e $18 \times 3 / 4$ $(7,14 \times 19,05 \mathrm{~mm})$. O percentual de sementes, para cada peneira, foi calculado por meio da relação entre o peso das sementes retidas em cada peneira e o peso da produção total das sementes de cada repetição (Brasil, 1992). Ressalta-se que nessa produção total incluía-se as sementes retidas na peneira 11x3/4 (4,37x19,05mm) e o fundo.

A análise estatística dos dados constou da análise de variância e aplicação do teste F, tendo-se comparado as médias pelo teste de Tukey a 5\%. Todos os cálculos foram realizados por meio do programa de computador ESTAT, conforme método descrito por Banzato \& Kronka (1989).

\section{RESULTADOS E DISCUSSÃO}

Os resultados da avaliação da qualidade fisiológica de sementes (germinação, primeira contagem, IVG e conduti- vidade elétrica), dos componentes da produção (número de sementes por planta e massa de 100 sementes) e da produtividade do feijoeiro encontram-se na Tabela 1. Verifica-se que não houve interação entre as doses aplicadas na semeadura com as de cobertura, para todas as variáveis analisadas. Portanto, os efeitos dos fatores doses na semeadura e em cobertura atuaram separadamente. Constata-se que não houve efeito do fator doses de $\mathrm{N}$ em cobertura sobre as variáveis estudadas. As diferentes doses de $\mathrm{N}$ na semeadura influenciaram isoladamente a primeira contagem, o IVG, a condutividade elétrica, o número de sementes por planta e a massa de 100 sementes.

No que se refere à germinação (Tabela 1), não houve efeito significativo da aplicação de $\mathrm{N}$, tanto em semeadura quanto em cobertura, sendo que todos os tratamentos apresentaram valores acima de $90 \%$, assim como observado por Carvalho et al. (1998b), trabalhando com a mesma cultivar, no período de inverno. O resultado obtido por Ambrosano et al. (1999), ao estudarem os efeitos da adubação nitrogenada na qualidade de sementes do feijoeiro cultivar IAC-Carioca, independente do parcelamento ou da dose utilizada, é corroborado pelo do presente trabalho, mostrando não haver influência sobre a germinação.

O teste de germinação é o método aplicado e recomendado para determinação da qualidade fisiológica da semente, embora se reconheçam as suas limitações, pois as condições a que as sementes são submetidas para germinar são próxi-

TABELA 1. Valores médios de germinação, primeira contagem, índice de velocidade de germinação (IVG), condutividade elétrica, número de sementes por planta, massa de 100 sementes e produtividade do feijão, cultivar IACCarioca, em função de doses de $\mathbf{N}$ na semeadura e em cobertura.

\begin{tabular}{|c|c|c|c|c|c|c|c|}
\hline Tratamentos & $\begin{array}{c}\text { Germinação } \\
(\%)\end{array}$ & $\begin{array}{c}\text { Primeira } \\
\text { contagem } \\
(\%) \\
\end{array}$ & IVG & $\begin{array}{c}\text { Condutividade } \\
\text { elétrica } \\
\left(\mu \mathrm{S} \mathrm{cm}^{-1} \mathrm{~g}^{-1}\right)\end{array}$ & $\begin{array}{c}\text { Número de } \\
\text { sementes/planta }\end{array}$ & $\begin{array}{l}\text { Massa de } 100 \\
\text { sementes }\end{array}$ & $\begin{array}{c}\text { Produtividade } \\
\text { de sementes } \\
\left(\mathrm{kg} \mathrm{ha}^{-1}\right)\end{array}$ \\
\hline \multicolumn{8}{|c|}{ Doses de N na Semeadura (S) } \\
\hline $0,0 \mathrm{~kg} \mathrm{ha}^{-1}$ & 93 & $86 a$ & $28,35 \mathrm{a}$ & $77 a$ & $63,7 \mathrm{~b}$ & $19,4 \mathrm{ab}$ & 1.081 \\
\hline $12,5 \mathrm{~kg} \mathrm{ha}^{-1}$ & 91 & $88 a$ & $28,19 a b$ & $71 \mathrm{a}$ & $100,4 a$ & $18,9 \mathrm{~b}$ & 1.276 \\
\hline $25,0 \mathrm{~kg} \mathrm{ha}^{-1}$ & 91 & $80 \mathrm{~b}$ & $27,20 \mathrm{~b}$ & $72 \mathrm{a}$ & $93,7 \mathrm{a}$ & $20,1 \mathrm{a}$ & 1.179 \\
\hline \multicolumn{8}{|c|}{ Doses de N em Cobertura (C) } \\
\hline $0,0 \mathrm{~kg} \mathrm{ha}^{-1}$ & 92 & 87 & 28,17 & 73 & 79,4 & 19,1 & 1.127 \\
\hline $12,5 \mathrm{~kg} \mathrm{ha}^{-1}$ & 92 & 84 & 27,88 & 74 & 83,9 & 19,7 & 1.155 \\
\hline $25,0 \mathrm{~kg} \mathrm{ha}^{-1}$ & 92 & 83 & 27,70 & 74 & 94,4 & 19,6 & 1.254 \\
\hline \multicolumn{8}{|c|}{ Valor de $\mathrm{F}^{(1)}$} \\
\hline Semeadura (S) & $1,43 \mathrm{~ns}$ & $10,61 * *$ & $4,73 *$ & $3,63 *$ & $4,46 *$ & $18,63 * *$ & $1,67 \mathrm{~ns}$ \\
\hline Cobertura (C) & 0,02 ns & 2,82 ns & 0,70 ns & $0,17 \mathrm{~ns}$ & $1,61 \mathrm{~ns}$ & $2,89 \mathrm{~ns}$ & $0,78 \mathrm{~ns}$ \\
\hline Interação S x C & $0,61 \mathrm{~ns}$ & 0,96 ns & 0,17 ns & 1,45 ns & $0,66 \mathrm{~ns}$ & $1,15 \mathrm{~ns}$ & 1,99 ns \\
\hline CV $(\%)$ & 3,36 & 5,48 & 3,54 & 8,40 & 18,23 & 4,92 & 22,06 \\
\hline
\end{tabular}

Comparam-se letras na vertical. Médias seguidas por letras iguais e sem letras nas colunas não diferem entre si pelo teste de Tukey a $5 \%$.

${ }^{(1)}$ Teste F: * significativo a 5\%; ** significativo a $1 \%$ e ns - não significativo. 
mas às adequadas (Bragantini, 1996). Se considerar que, independente do tratamento, a germinação variou de 91 a $93 \%$ (Tabela 1), e o valor mínimo para a comercialização de sementes de feijão, para a maioria dos Estados brasileiros fica entre 80 a $85 \%$ (Carvalho et al., 2001), todos os tratamentos produziram sementes aptas para comercialização, mesmo em cultivo "das águas".

Quanto ao vigor, avaliado com base na primeira contagem e no IVG, verifica-se efeito significativo da aplicação de $\mathrm{N}$ na semeadura (Tabela 1), onde a maior dose $\left(25,0 \mathrm{~kg} \mathrm{ha}^{-1}\right)$ reduziu os valores dessas duas variáveis em relação à testemunha. Com relação à primeira contagem, observa-se que mesmo nessa maior dose as sementes apresentaram dentro dos padrões de qualidade, que sugerem uma germinação mínima de 80\% para o feijoeiro (Carvalho et al., 1998b), independente da dose e época da adubação nitrogenada. Resultado esse concordante com os obtidos por Carvalho et al. (1998b) e Ambrosano et al. (1999).

Deve-se ressaltar que para a condutividade elétrica, apesar de influenciada significativamente pelo $\mathrm{N}$ na semeadura, conforme valor de $\mathrm{F}$ apresentado, o teste de comparação de médias não detectou diferença estatística entre tratamentos (Tabela 1). Portanto, pode-se inferir que o comportamento entre os tratamentos se mantiveram dentro de um mesmo padrão, o qual sugere não ter havido modificações significativas nas sementes, capazes de proporcionar uma lixiviação de eletrólitos diferenciada, em função das doses de $\mathrm{N}$ aplicadas na semeadura.

Sabendo-se que a qualidade fisiológica diz respeito a atributos intrínsecos à semente, os quais determinam a capacidade potencial em gerar uma nova planta, perfeita e vigorosa, sob condições favoráveis ou não (Ambrosano et al., 1999 e Vieira \& Rava, 2000), é possível afirmar que o fornecimento diferencial de $\mathrm{N}$ não melhorou a qualidade fisiológica das sementes, nas condições do presente estudo. Conclusão semelhante foi obtida por Ambrosano et al. (1999), ao avaliarem a percentagem de germinação e de plântulas anormais. Também, Andrade et al. (1999) não observaram efeito da adubação nitrogenada sobre a qualidade fisiológica das sementes de feijoeiro, pelos testes de vigor utilizados (comprimento da radícula e do hipocótilo). Assim como o ocorrido no presente trabalho, Carvalho et al. (2001), estudando a influência do parcelamento de N, não verificaram consistência quanto aos efeitos sobre o vigor das sementes de feijão cultivar IAC-Carioca, avaliado por meio da primeira contagem, IVG, envelhecimento acelerado e emergência de plântulas em campo.
Quanto ao número de sementes por planta (Tabela 1), os tratamentos que receberam as doses de $\mathrm{N}$ na semeadura (12,5 e $25,0 \mathrm{~kg} \mathrm{ha}^{-1}$ ) foram estatisticamente superiores à testemunha. Esse resultado se assemelha aos obtidos por Carvalho et al. (2001), onde as maiores doses na semeadura (60 e $75 \mathrm{~kg}$ ha $^{-1}$ de N) proporcionaram número de sementes por planta significativamente superiores à testemunha. Para os dois casos anteriores, a aplicação de doses de $\mathrm{N}$ na semeadura pode estimular o aumento do número de vagens por planta, elevando, assim, o número de sementes por planta (Carvalho et al., 2001).

$\mathrm{O}$ não efeito significativo de doses de $\mathrm{N}$ em cobertura sobre o número de sementes por planta (Tabela 1), apesar de verificar-se tendência no aumento dessa variável, está de acordo com os resultados obtidos por Carvalho et al. (1998a) e Almeida et al. (2000), que utilizaram a mesma cultivar.

Com relação à massa de 100 sementes (Tabela 1), verifica-se que a dose de $25,0 \mathrm{~kg} \mathrm{ha}^{-1}$ de $\mathrm{N}$ na semeadura proporcionou valor significativamente superior ao obtido com 12,5 $\mathrm{kg} \mathrm{ha}^{-1}$, porém os dois tratamentos não diferiram significativamente da testemunha. Da mesma forma, Carvalho et al. (2001) constataram que sem a aplicação de $\mathrm{N}$ a massa de 100 sementes não diferiu em relação a maior dose de $\mathrm{N}$ aplicada na semeadura.

A não resposta das doses de $\mathrm{N}$ em cobertura sobre a massa de 100 sementes (Tabela 1), corrobora com os resultados encontrados por Richart et al. (1998) e por Almeida et al. (2000). Entretanto, discorda dos resultados obtidos por Diniz et al. (1996), que verificaram que a aplicação de $30 \mathrm{~kg} \mathrm{ha}^{-1}$ de N em cobertura aumentou a massa de 100 sementes, em relação à testemunha.

Considerando o efeito isolado de $\mathrm{N}$, na semeadura e em cobertura, o aumento da dose não proporcionou a elevação da produtividade de sementes de feijão (Tabela 1). Esse resultado está de acordo com os alcançados por Silva et al. (1999), os quais concluíram que o aumento significativo de alguns componentes da produção, pela aplicação de doses crescentes de $\mathrm{N}$ no solo, nem sempre aumentam a produtividade. Para Carvalho et al. (1998a e 2001), os valores da produtividade do feijão, também, não se diferenciaram, em função do $\mathrm{N}$ aplicado na semeadura ou em cobertura. No entanto, sabe-se que uma planta nutrida adequadamente apresenta melhores condições de proporcionar maiores níveis de produtividade (Carvalho et al., 2001), pois com insuficiência no suprimento de nutrientes, incluindo-se sobretudo o N, há redução do ciclo, que causa diminuição no número de flores e vagens fixadas, má formação dos frutos e interferência na 
maturação. Nesse sentido, Almeida et al. (2000) constataram que o fornecimento de $\mathrm{N}$ via solo provocou aumento na produtividade do feijoeiro. Andrade et al. (1999) verificaram efeito negativo, ou seja, à medida que se aumentava o $\mathrm{N}$ ocorria diminuição da produtividade. Portanto, os resultados encontrados na literatura a respeito dos efeitos da adubação nitrogenada sobre a produtividade de sementes de feijão, ainda, são controvertidos.

No presente trabalho, provavelmente o alto teor de M.O. do solo (6,5 $\mathrm{g} \mathrm{dm}^{-3}$ ), assim como a elevada precipitação pluvial (561mm), podem ter interferido na resposta do feijoeiro à adubação nitrogenada. Considera-se que acima de $2,5 \mathrm{~g} \mathrm{dm}^{-3} \mathrm{a}$ M.O. é alta suficiente para interferir na resposta do feijoeiro ao N aplicado (Vieira et al., 1999), sendo provável que a maior parte do $\mathrm{N}$ necessário ao crescimento e responsável pelas médias de produtividade (Tabela 1), tenha sido oriundo da mineralização da M.O.. É possível, também, que a simbiose do feijoeiro com estirpes de bactéria do gênero Rhizobium, já estabelecidas no solo, tenham proporcionado fixação do Natmosférico, beneficiando, em parte, a nutrição da cultura. No entanto, nem sempre os rizóbios naturalizados são eficientes na fixação de $\mathrm{N}_{2}$, contribuindo pouco no fornecimento de $\mathrm{N}$ ao feijoeiro (Oliveira et al., 1996).

Na Tabela 2, estão apresentados os valores percentuais da classificação de sementes por peneira, para cada tratamento, em função do efeito isolado dos fatores doses de $\mathrm{N}$ na semeadura e em cobertura, pois não ocorreram interações signifi- cativas. Para todas as peneiras, não foi constatada a ação significativa do $\mathrm{N}$ na semeadura. Quanto à dose de $\mathrm{N}$ em cobertura, verifica-se que proporcionou efeito significativo para algumas peneiras, sendo que a maior dose (25,0 kg ha-1) ocasionou redução percentual das sementes retidas nas peneiras 14 e 15, e elevou a proporção na 17 e 18, ou seja, aumentou a proporção das maiores.

Carvalho et al. (2001) consideraram como sementes de classificação comercial de feijão cultivar IAC-Carioca, aquelas retidas nas peneiras oblongas 11,12 , 13 e 14 . Se for considerada essa classificação, verifica-se na Tabela 2 que, independente da aplicação do N-mineral, houve pequena quantidade de materiais comerciais considerados pelos referidos autores (peneiras 12, 13 e 14), sendo maior a percentagem de sementes com maior acúmulo de reservas (peneiras 15, 16, 17 e 18). Isso indica que nesse experimento, as sementes foram maiores, provavelmente, em função das condições ambientais terem sido mais favoráveis ao crescimento delas, pois foi cultivado na época “das águas”, enquanto o experimento conduzido por Carvalho et al. (2001) ocorreu no inverno.

As sementes de maior tamanho geram plântulas com maior conteúdo de massa seca, conseqüência do maior acúmulo de reservas e posterior utilização na constituição dos órgãos (Fornasieri-Filho et al., 1996). Assim sendo, esperase que lavouras geradas por sementes maiores apresentem maior produtividade devido à maior quantidade de tecido de

TABELA 2. Resultados médios da classificação por peneiras de crivos oblongos de sementes de feijão, para o cultivar IAC-Carioca, em função de doses de $\mathrm{N}$ na semeadura e em cobertura.

\begin{tabular}{|c|c|c|c|c|c|c|c|}
\hline \multirow{2}{*}{ Tratamentos } & \multicolumn{7}{|c|}{ Percentual de sementes retidas / peneira (\%) } \\
\hline & Peneira 12 & Peneira 13 & Peneira 14 & Peneira 15 & Peneira 16 & Peneira 17 & Peneira 18 \\
\hline \multicolumn{8}{|c|}{ Doses de N na Semeadura (S) } \\
\hline $0,0 \mathrm{~kg} \mathrm{ha}^{-1}$ & 0,23 & 4,64 & 12,60 & 30,16 & 34,04 & 11,47 & 3,77 \\
\hline $12,5 \mathrm{~kg} \mathrm{ha}^{-1}$ & 0,24 & 4,18 & 10,52 & 28,24 & 37,81 & 12,41 & 3,54 \\
\hline $25,0 \mathrm{~kg} \mathrm{ha}^{-1}$ & 0,35 & 4,69 & 10,55 & 27,92 & 38,16 & 12,22 & 3,64 \\
\hline \multicolumn{8}{|c|}{ Doses de N em Cobertura (C) } \\
\hline $0,0 \mathrm{~kg} \mathrm{ha}^{-1}$ & 0,30 & 5,20 & $13,70 \mathrm{a}$ & $31,49 a$ & 34,31 & $9,49 \mathrm{~b}$ & $2,47 \mathrm{~b}$ \\
\hline $12,5 \mathrm{~kg} \mathrm{ha}^{-1}$ & 0,25 & 4,12 & $10,46 a b$ & $27,63 \mathrm{~b}$ & 38,08 & $12,64 \mathrm{ab}$ & $4,05 \mathrm{a}$ \\
\hline $25,0 \mathrm{~kg} \mathrm{ha}^{-1}$ & 0,28 & 4,19 & $9,51 \quad b$ & 27,19 b & 37,63 & $13,96 \mathrm{a}$ & $4,44 a$ \\
\hline \multicolumn{8}{|c|}{ Valor de $\mathrm{F}^{(1)}$} \\
\hline Semeadura (S) & $1,94 \mathrm{~ns}$ & $0,25 \mathrm{~ns}$ & $1,20 \mathrm{~ns}$ & $1,80 \mathrm{~ns}$ & $1,99 \mathrm{~ns}$ & $0,23 \mathrm{~ns}$ & 0,09 ns \\
\hline Cobertura (C) & $0,24 \mathrm{~ns}$ & $1,17 \mathrm{~ns}$ & $4,05 *$ & $6,82 *$ & $1,62 \mathrm{~ns}$ & $4,93 *$ & $7,08 * *$ \\
\hline Interação S x C & $0,39 \mathrm{~ns}$ & $0,95 \mathrm{~ns}$ & $1,88 \mathrm{~ns}$ & $2,33 \mathrm{~ns}$ & $1,25 \mathrm{~ns}$ & $1,45 \mathrm{~ns}$ & $0,34 \mathrm{~ns}$ \\
\hline CV (\%) & 59,85 & 43,13 & 33,68 & 10,90 & 15,26 & 29,78 & 37,15 \\
\hline
\end{tabular}

Comparam-se letras na vertical. Médias seguidas por letras iguais e sem letras nas colunas não diferem entre si pelo teste de Tukey a 5\%.

${ }^{(1)}$ Teste F: * significativo a 5\%; ** significativo a $1 \%$ e ns - não significativo. 
reserva. Já, a utilização de sementes pequenas é mais econômica aos agricultores, uma vez que é necessária uma menor quantidade (em peso) para a semeadura (Lima \& Carmona, 1999).

No caso do feijão, cultivar IAC-Carioca, Delavale et al. (1999) não observaram diferença significativa entre as peneiras, demonstrando que o tamanho da semente não influenciou as variáveis germinação, primeira contagem, IVG e condutividade elétrica. No entanto, o efeito do tamanho das sementes na sua qualidade fisiológica e desempenho em condições de campo, demanda ações da pesquisa que propiciem a adequada orientação das instituições produtoras e comercializadoras de sementes (Marcos-Filho \& Avancine, 1983).

\section{CONCLUSÕES}

- As doses de $\mathrm{N}$ aplicadas não se mostraram consistentes quanto aos seus efeitos sobre a qualidade fisiológica, avaliada logo após a colheita, podendo-se afirmar que não houve efeito favorável da adubação nitrogenada sobre a germinação e o vigor de sementes de feijão;

- o fornecimento da maior dose de $\mathrm{N}$ na semeadura (25,0 $\mathrm{kg} \mathrm{ha}^{-1}$ ) provocou o aumento dos valores dos componentes da produção, mas sem proporcionar a elevação da produtividade;

- A disponibilidade de $\mathrm{N}$, pela adubação nitrogenada de cobertura, proporcionou aumento no tamanho das sementes de feijão.

\section{REFERÊNCIAS}

ALMEIDA, C.; CARVAlHO, M.A.C.; ARF, O.; SÁ, M.E.; BUZETTI, S. Uréia em cobertura e via foliar em feijoeiro. Scientia Agricola, Piracicaba, v.57, n.2, p.293-298, 2000.

AMBROSANO, E.J.; WUTKE, E.B.; AMBROSANO, G.M.B.; BULISANI, E.A.; BORTOLETTO, ; MARTINS, A.L.M.; PEREIRA, J.C.V.N.A.; DE SORDI, G. Efeito do nitrogênio no cultivo de feijão irrigado no inverno. Scientia Agricola, Piracicaba, v.53, n.2, p.338342, 1996.

AMBROSANO, E.J.; AMBROSANO, G.M.B.; WUTKE, E.B.; BULISANI, E.A.; MARTINS, A.L.M. \& SILVEIRA, L.C.P. Efeitos da adubação nitrogenada e com micronutrientes na qualidade de sementes do feijoeiro cultivar IAC - Carioca. Bragantia, Campinas, v.58, n.2, p.393-399, 1999.

ANDRADE, W.E.B.; SOUZA-FILHO, B.F.; FERNANDES, G.M.B.; SANTOS, J.G.C. Avaliação da produtividade e da qualidade fisiológica de sementes de feijoeiro submetidas à adubação NPK.
In: COMUNICADO TÉCNICO. Niteroi: PESAGRO-RIO, n.248, 5p., 1999.

AOSA - ASSOCIATION OF OFFICIAL SEED ANALYSIS. Seed vigour testing handbook. East Lansing, 1983. 88p.

BANZATO, D.A.; KRONKA, S.N. Experimentação agrícola. Jaboticabal: FUNEP, 1989. 247p.

BRAGANTINI, C. Produção de sementes. In: ARAUJO, R.S.; RAVA, C.A.; STONE, L.F.; ZIMMERMANN, M.J. (eds.). Cultura do feijoeiro comum no Brasil. Piracicaba: POTAFOS, 1996. p.639667.

BRASIL. Ministério da Agricultura e da Reforma Agrária. Regras para análise de sementes. Brasília: SNDA/DNDV/CLAV, 1992. 365p.

CARVALHO, E.G.; ARF, O.; SÁ, M.E.; BUZETTI, S. Efeito de nitrogênio, molibdênio e inoculação das sementes em feijoeiro (Phaseolus vulgaris L.) na região de Selvíria, MS: I. Produção de sementes. Científica, São Paulo, v.26, n.1/2, p.45-58, 1998a.

CARVALHO, E.G.; ARF, O.; SÁ, M.E. \& BUZETTI, S. Efeito de nitrogênio, molibdênio e inoculação das sementes em feijoeiro (Phaseolus vulgaris L.) na região de Selvíria, MS: II. Qualidade fisiológica e desempenho das sementes em campo. Científica, São Paulo, v.26, n.1/2, p.59-71, 1998b.

CARVALHO, M.A.C.; ARF, O.; SÁ, M.E.; BUZETTI, S.; SANTOS, N.C.B.; BASSAN, D.A.Z. Produtividade e qualidade de sementes de feijoeiro (Phaseolus vulgaris L.) sob influência de parcelamento e fontes de nitrogênio. Revista Brasileira de Ciência do Solo, Campinas, v.25, n.3, p.617-624, 2001.

CARVALHO, N.M.; NAKAGAWA, J. Sementes: ciência, tecnologia e produção. Jaboticabal: FUNEP, 2000. 588p.

DELAVALE, F.G.; CARVALHO, M.A.C.; JUSTI, M.M.; SÁ, M.E.; ARF, O. Influência do tamanho na qualidade fisiológica de sementes de feijoeiro (Phaseolus vulgaris L.). In: REUNIÂO NACIONAL DE PESQUISA DE FEIJÃO, 6, Salvador, 21/26 nov. 1999. Resumos Expandidos. Goiânia: EMBRAPA, 1999. p.570-571.

DELOUCHE, J.C. Metodologia de pesquisa em sementes: III. Vigor, envigoramento e desempenho no campo. Revista Brasileira de Sementes, Brasília, v.3, n.2, p.57-64, 1981.

DINIZ, A.R.; ANDRADE, M.J.B.; CARVALHO, J.G.; LIMA, S.F.; LUNKES, J.A. Resposta da cultura do feijão (Phaseolus vulgaris L.) à aplicação de nitrogênio (cobertura e semeadura) e de molibdênio foliar. In: REUNIÃO NACIONAL DE FEIJÃO, 5, Goiânia, 14/18 out. 1996. Anais. Goiânia: EMBRAPA/CNPAF, 1996. p.73-75.

EMBRAPA - Centro Nacional de Pesquisa de Solo. Sistema brasileiro de classificação de solos. Brasília, 1999. 412p.

FERNÁNDEZ, F.; GEPTS, P. \& LÓPEZ, M. Etapas de desarrollo em la planta de frijol. In:

LÓPEZ, M.; FERNÁNDEZ, F.; SCHOONHOVEN, A. van. (eds.). Frijol: investigación y producción. Cali: CIAT, 1985. p.61-78.

FORNASIERI-FILHO, D.; FRATTINI, N.; VIEIRA, R.D.; LEMOS, L.B. Efeito do tamanho da sementes e de doses de fungicida na qualidade fisiológica de sementes de feijoeiro. In: REUNIÃO 
NACIONAL DE FEIJÃO, 5, Goiânia, 14/18 out. 1996. Anais. Goiânia: EMBRAPA/CNPAF, 1996. p.512-514.

LIMA, A.M.M.P.; CARMONA, R. Influência do tamanho da semente no desempenho produtivo da soja. Revista Brasileira de Sementes, Brasília, v.21, n.1, p.157-163, 1999.

MAGUIRE, L.D. Speed of germination-aid in selection and evolution for seedling emergence and vigor. Crop Science, Madison, v.2, n.2, p.176-177, 1962.

MARCOS-FILHO, J.; AVANCINE, F. Tamanho da semente de feijão e desempenho do feijoeiro. Pesquisa Agropecuária Brasileira, Brasília, v.18, n.9, p.1001-1008, 1983.

OLIVEIRA, I.P.; ARAUJO, R.S.; DUTRA, L.G. Nutrição mineral e fixação biológica de nitrogênio. In: ARAUJO, R.S.; RAVA, C.A.; STONE, L.F.; ZIMMERMANN, M.J. (eds.). Cultura do feijoeiro comum no Brasil. Piracicaba: POTAFOS, 1996. p.169-221.

PUZZI, D. Abastecimento e armazenamento de grãos. Campinas: Instituto Campineiro de Ensino Agrícola, 1986. 603p.

RICHART, A.; PESSOA, A.C.S.; LUCHESE, E.B.; CAVALLET, L.E.; KUHN, O.J. Produtividade do feijoeiro "FT Nobre" em resposta ao manejo da adubação nitrogenada e à adubação foliar com molibdênio. In: REUNIÃO BRASILEIRA DE FERTILIDADE DO SOLO E NUTRIÇÃO DE PLANTAS, 23; REUNIÃO BRASILEIRA SOBRE MICORRIZAS, 7; SIMPÓSIO BRASILEIRO DE MICROBIOLOGIA DO SOLO, 5; REUNIÃO BRASILEIRA DE BIOLOGIA DO SOLO, 2, Caxambu, 11/16 out. 1998. Resumos. Caxambu: Universidade Federal de Lavras, 1998. p.478.

SILVA, T.R.B.; SORATTO, R.P.; CHIDI, S.N.; ARF, O.; BUZETTI, S. Efeito de doses e da época de aplicação de nitrogênio em cobertura na cultura do feijão (Phaseolus vulgaris L.) no período de inverno: I. Características agronômicas. In: REUNIÃO NACIONAL DE
PESQUISA DE FEIJÃO, 6, Salvador, 21/26 nov. 1999. Resumos Expandidos. Goiânia: EMBRAPA, 1999. p.805-808.

VALÉRIO, C.R.; ANDRADE, M.J.B.; FURTADO, D.F. Resposta do feijoeiro comum (Phaseolus vulgaris L.) a doses de nitrogênio aplicadas no plantio e em cobertura. In: REUNIÃO NACIONAL DE PESQUISA DE FEIJÃO, 6, Salvador, 21/26 nov. 1999. Resumos Expandidos. Goiânia: EMBRAPA, 1999. p.866-867.

VIEIRA, R.F.; VIEIRA, C.; RAMOS, J.A.O. Produção de sementes de feijão. Viçosa: EPAMIG/EMBRAPA, 1993. 131p.

VIEIRA, R.D. Teste de condutividade elétrica. In: VIEIRA, R.D.; CARVALHO, N.M. (eds.). Teste de vigor em sementes. Jaboticabal: FUNEP, 1994. p.133-149.

VIEIRA, C. Adubação mineral e calagem. In: VIEIRA, C.; PAULAJUNIOR, T.J.; BORÉM, A. (eds.). Feijão: aspectos gerais e cultura no Estado de Minas Gerais. Viçosa: UFV, 1998. p.123-152.

VIEIRA, S.M.; RONZELLI-JUNIOR, P.; KOEHLER, H.S.; PREVEDELLO, B.M.S. Nitrogênio, molibdênio e inoculante, isolados e associados para duas variedades de feijoeiro comum. In: REUNIÃO NACIONAL DE PESQUISA DE FEIJÃO, 6, Salvador, 21/26 nov. 1999. Resumos Expandidos. Goiânia: EMBRAPA, 1999. p.835-838.

VIEIRA, E.H.N.; RAVA, C.A. Características botânicas e fisiológicas da semente. In: VIEIRA, E.H.N. \& RAVA, C.A. (eds.). Sementes de feijão: produção e tecnologia. Santo Antônio de Goiás: EMBRAPA, 2000. p.25-38.

YOKOYAMA, L.P.; WETZEL, C.T.; VIEIRA, E.H.N.; PEREIRA, G.V. Sementes de feijão: produção, uso e comercialização. In: VIEIRA, E.H.N. \& RAVA, C.A. (eds.). Sementes de feijão: produção e tecnologia. Santo Antônio de Goiás: EMBRAPA, 2000. p.249-270. 